\title{
Investigating Students' Perception on the Outcomes of Technical Drawing University Courses
}

\author{
Barbara Motyl $^{1(\bowtie)}$, Stefano Filippi ${ }^{1}$, Gabriele Baronio ${ }^{2}$, and Domenico Speranza ${ }^{3}$ \\ 1 DPIA, University of Udine, Udine, Italy \\ barbara.motyleuniud.it \\ 2 DIMI, University of Brescia, Brescia, Italy \\ 3 DICEM, University of Cassino and Southern Lazio, Cassino, Italy
}

\begin{abstract}
This paper presents the results of a survey carried out with students enrolled in the first two years of the BS in Engineering at three Italian university locations. The study is part of a wider range of methods, tools and aids for the improvement of teaching and learning of technical drawing at university level developed by the University of Brescia, Udine, and Cassino and Southern Lazio. In particular, this work analyses the results of questionnaires related to the basic technical drawing outcomes, taking inspiration from previous research work in this field. What emerges is a positive picture that shows students' interest in $3 \mathrm{D}$ CAD modeling topics such as part or assembly construction, but also their interest in more traditional subjects like sketching and dimensioning.
\end{abstract}

Keywords: Technical drawing · CAD · Engineering education · Students' surveys

\section{Introduction}

This work is part of a research aimed at improving teaching and learning of technical drawing (TD) for BS courses in Engineering. As mentioned in previous works [1-5], the Universities of Brescia, Udine and Cassino and Southern Lazio have been collaborating on these themes since 2014. In this paper, the authors analyze the results of questionnaires proposed to first years students in Industrial or Mechanical Engineering during the academic year 2016-2017. One of the goals of the survey is to clarify what students think and what are their opinions on some outcomes related to TD.

After the background section summarizing the reasons for this survey and the sources chosen as starting points, section two describes the survey contents and the working methodology adopted. In section three the results are reported while in section four they are analyzed and discussed. Finally, conclusions and possible future developments are pointed out. 


\section{Background}

The starting point for structuring the questionnaire and for selecting the questions to use was the work of Barr [6, 7], where he discusses the current state of engineering graphical communication in Engineering Education in the US. In particular, Barr defined some educational outcomes for technical drawing or engineering graphics (as this discipline is called in USA). He chose fourteen potential outcomes and conducted a survey by interviewing a few colleagues to assess their importance and to understand which one could be introduced as part of an engineering graphics course. In particular, these fourteen outcomes are related to traditional technical drawing, 2D and 3D CAD topics.

Table 1. Barr's fourteen outcomes and the results of the 2004 and 2012 surveys [6, 7].

\begin{tabular}{l|l|l|l}
\hline Label & Description & $\begin{array}{l}\text { Average score } \\
2004\end{array}$ & $\begin{array}{l}\text { Average score } \\
2012\end{array}$ \\
\hline O1 & $\begin{array}{l}\text { Ability to sketch engineering objects in the free } \\
\text { hand mode }\end{array}$ & 4,67 & 4,54 \\
\hline O2 & $\begin{array}{l}\text { Ability to create geometric construction with hand } \\
\text { tools }\end{array}$ & 2,13 & 2,71 \\
\hline O3 & Ability to create 2D computer geometry & 4,21 & 4,08 \\
\hline O4 & Ability to create 3D solid computer models & 4,75 & 4,75 \\
\hline O5 & Ability to visualize 3D solid computer models & 4,46 & 4,54 \\
\hline O6 & Ability to create 3D assemblies of computer models & 4,29 & 4,54 \\
\hline O7 & Ability to analyze 3D computer models & 3,71 & 4,13 \\
\hline O8 & $\begin{array}{l}\text { Ability to ability to generate engineering drawings } \\
\text { from computer models }\end{array}$ & 4,33 & 4,29 \\
\hline O9 & Ability to create section views & 4,13 & 4,33 \\
\hline O10 & Ability to create dimensions & 4,38 & 4,38 \\
\hline O11 & $\begin{array}{l}\text { Knowledge of manufacturing and Rapid } \\
\text { Prototyping methods }\end{array}$ & 3,42 & 3,63 \\
\hline O12 & $\begin{array}{l}\text { Ability to solve traditional descriptive geometry } \\
\text { problems }\end{array}$ & 2,29 & 2,75 \\
\hline O13 & Ability to create presentations & 3,42 & 3,46 \\
\hline O14 & Ability to perform design projects & 3,96 & 4,08 \\
\hline & & &
\end{tabular}

In his surveys, Barr proposed to evaluate their importance to twenty-four engineering graphics faculty and members of the Engineering Design Graphics Division of the ASEE, (https://edgd.asee.org/), asking to rank each outcome using a numerical scale from 1 to 5 , where 1 corresponds to "Not Important at all" and 5 to "Very Important". The survey was conducted twice, first in 2004 and again in 2012. The results of these surveys can be summarized as follows. In addition to the predominance of CAD-related outcomes in the results of the surveys, some traditional outcomes like sketching, dimensioning 
and sectioning, are also perceived as important by the interviewed people. Therefore, as reported by Barr, there is still a perception of the need to teach graphic fundamentals in Engineering Education [6]. Table 1 reports the fourteen outcomes and the average scores obtained in the 2004 and in the 2012 surveys [6, 7].

\section{The Survey}

Thus, taking inspiration from the Barr's outcomes, from the literature on latest technological and educational trends [8,9] and from the experience of the authors as instructors and researchers [10], a questionnaire has been developed to propose online to students of the first years of Engineering courses in the three Universities involved. The questionnaire consisted of twenty-six questions. The first fourteen questions were related to the Barr's outcomes and the students were asked to evaluate them using the same one-to-five scale. Ten questions were related to Industry 4.0 topics, to the use of educational support tools such as smartphones, tablets, personal computers, learning management systems and specific CAD software. In addition, there were two open questions to collect the students' opinion about their possible participation at design competitions and about the TD course in general.

Table 2. Data relating to the sample of students interviewed.

\begin{tabular}{l|c|c|c|c|c}
\hline & Students & \multicolumn{2}{|l|}{ Male (\#; \%) } & \multicolumn{2}{l}{ Female (\#; \%) } \\
\hline Brescia & 97 & 88 & 90,7 & 9 & 9,3 \\
\hline Cassino & 128 & 105 & 82,1 & 23 & 17,9 \\
\hline Udine & 70 & 55 & 78,6 & 15 & 21,4 \\
\hline TOTAL & 295 & 248 & 84,1 & 47 & 15,9 \\
\hline
\end{tabular}

This paper focuses the analysis on the results obtained thanks to the fourteen questions concerning the Barr's outcomes to put our recent results (academic year 2016-2017) into relationship with the Barr's recent ones (2012), although the former refers to students and the latter to teachers. The questionnaire has been proposed to 295 students during the first lessons of the TD courses at the three university locations during the academic year 2016-2017. Table 2 shows the data relating to the sample of students interviewed.

\section{Results}

Table 3 shows the results of the survey; they appear both divided by university and as totals. The average scores for each single question have been calculated to get an easier reasoning about these results and in order to make the comparison to the values obtained by Barr feasible. 
Table 3. Results obtained for the 14 outcomes during the survey.

\begin{tabular}{l|l|l|l|l}
\hline \multirow{2}{*}{ Outcome } & \multicolumn{4}{l}{ Average scores } \\
\cline { 2 - 5 } & Brescia & Cassino & Udine & Total \\
\hline O1 & 3,68 & 4,16 & 3,70 & 3,89 \\
\hline O2 & 3,87 & 3,96 & 3,70 & 3,87 \\
\hline O3 & 4,36 & 4,55 & 4,36 & 4,44 \\
\hline O4 & 4,52 & 4,54 & 4,29 & 4,47 \\
\hline O5 & 4,56 & 4,45 & 4,31 & 4,45 \\
\hline O6 & 4,19 & 4,06 & 3,84 & 4,05 \\
\hline O7 & 4,34 & 4,35 & 4,24 & 4,32 \\
\hline O8 & 4,03 & 4,05 & 3,81 & 3,99 \\
\hline O9 & 4,11 & 4,29 & 3,90 & 4,14 \\
\hline O10 & 4,42 & 4,55 & 4,20 & 4,42 \\
\hline O11 & 3,72 & 3,85 & 3,66 & 3,76 \\
\hline O12 & 3,70 & 4,06 & 3,56 & 3,82 \\
\hline O13 & 4,33 & 4,02 & 4,13 & 4,15 \\
\hline O14 & 3,76 & 4,38 & 4,10 & 4,11 \\
\hline
\end{tabular}

\section{Discussion}

The results are analyzed both individually, for each of the three sites involved, and in an aggregate way, reasoning on the total average scores and comparing them with the values of the 2012 survey conducted by Barr [7]. Considering each university, what emerges from the analysis of the average scores obtained for the various outcomes is as follows.

The students at the University of Brescia considered $\mathrm{O} 5, \mathrm{O} 4$, and $\mathrm{O} 10$ as the most important outcomes, while $\mathrm{O} 1$ was the least important. In Cassino, the outcomes considered as the most important were $\mathrm{O} 3, \mathrm{O} 10$, and $\mathrm{O} 4$, while $\mathrm{O} 11$ was the least important. In Udine, the $\mathrm{O} 3, \mathrm{O} 5$, and $\mathrm{O} 4$ outcomes were considered the most interesting, while $\mathrm{O} 12$ was considered the least attractive. All of this highlights quite clearly the students' interest in 3D CAD modeling (O4), even if the dimensioning (O10) also represents one of the most interesting topics in two out of the three locations. On the other hand, considering the data in the aggregated way, the totals confirm $\mathrm{O} 4, \mathrm{O} 5$ and $\mathrm{O} 3$ as the most interesting outcomes, followed by O10. Conversely, the least attractive are O11, O12 and O2. If these data report the opinion of students at the time of their entry into university courses, please consider now what can be said by comparing these data with those obtained by Barr in 2012, referred to teachers' opinions rather than students' ones. Figure 1 reports 
the histogram comparing the average scores of the three Universities, the total average scores and the Barr's values, all of this for each of the fourteen outcomes.

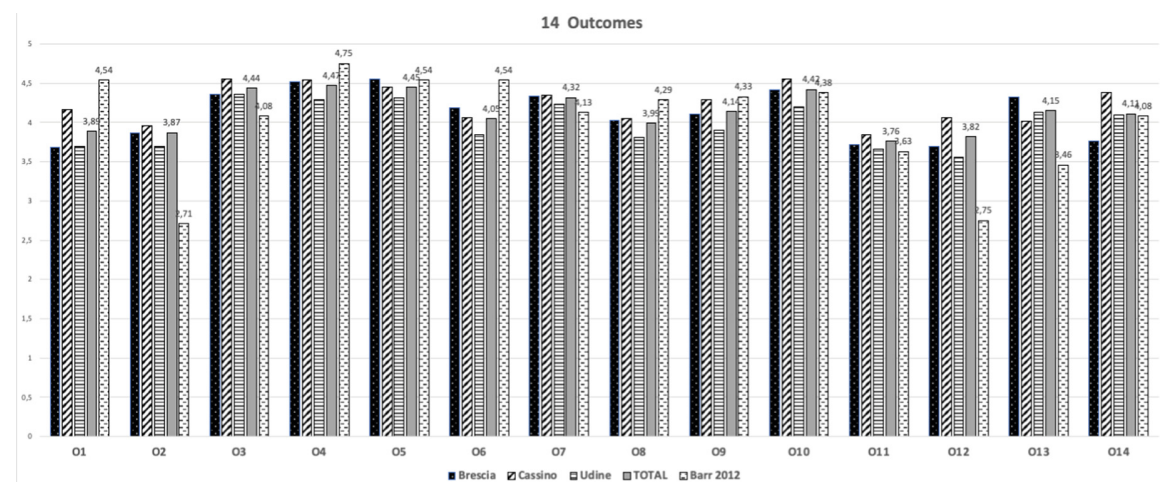

Fig. 1. Average scores in the three Universities, as totals and from Barr's 2012 survey [7].

Basically, there is a correspondence between the students and teachers' opinions, despite the difference in time. In fact, both show greater interest in 3D CAD topics in general (modeling of parts, visualization, creation of assemblies), even if some more traditional topics such as hand drawing (O1) and dimensioning (O10) are reputed as interesting as well. Only $\mathrm{O} 1, \mathrm{O} 2, \mathrm{O} 12$ and $\mathrm{O} 13$ show discrepancies. O1 seems to be more interesting for teachers while the other three appear as more interesting for students. This could be due to several factors; for example, the time distance between our investigation and the one carried out by Barr, but above all the different level of experience with TD related topics held by the students and the teaching staff.

\section{Conclusion and Future Developments}

The survey investigating students' perception on TD topics proposed during the BS courses had interesting results. It allowed getting an updated and wider picture of what students think about TD, showing that they are aware of the different outcomes related to it and that even if there is a clear interest in the most modern topics like 3D and 2D $\mathrm{CAD}$, more traditional and fundamental topics such as sketching and dimensioning must not be neglected.

These results pushed the authors to plan to propose the questionnaire every year from now on and to make it available also to other interested Universities. The data collected throughout will allow verifying the goodness of the questionnaire in terms of completeness and robustness. Moreover, all of this will allow highlighting and dealing with possible bias due to the design and selection of the questions.

Acknowledgments. The authors would like to thank all the engineering students who participated at the survey during the Academic Year 2016-17. 


\section{References}

1. Speranza, D., Baronio, G., Motyl, B., Filippi, S., Villa, V.: Best practices in teaching technical drawing: experiences of collaboration in three Italian Universities. In: Eynard, B., Nigrelli, V., Oliveri, S.M., Peris-Fajarnes, G., Rizzuti, S. (eds.) Advances on Mechanics, Design Engineering and Manufacturing. LNCS, pp. 903-913. Springer, Cham (2017). https://doi.org/10. 1007/978-3-319-45781-9_90

2. Baronio, G., Motyl, B., Paderno, D.: Technical Drawing Learning Tool-Level 2: an interactive self-learning tool for teaching manufacturing dimensioning. Comput. Appl. Eng. Educ. 24(4), 519-528 (2016). https://doi.org/10.1002/cae.21728

3. Villa, V., Motyl, B., Paderno, D., Baronio, G.: TDEG based framework and tools for innovation in teaching technical drawing: the example of LaMoo project. Comput. Appl. Eng. Educ. 26(5), 1293-1305 (2018). https://doi.org/10.1002/cae.22022

4. Baronio, G., Bodini, I., Copeta, A., Dassa, L., Grassi, B., Metraglia, R., Motyl, B., Paderno, D., Uberti, S., Villa, V.: Integrated approach to the innovation of technical drawing teaching methods. In: Cavas-Martínez, F., Eynard, B., Fernández, C.F., Fernández-Pacheco, D., Morer, P., Nigrelli, V. (eds.) Advances on Mechanics, Design Engineering and Manufacturing II. LNCS, pp. 705-713. Springer, Heidelberg (2019). https://doi.org/10.1007/978-3-030-123468 8_68

5. Motyl, B., Baronio, G., Speranza, D., Filippi, S. TDT-L0 a test-based method for assessing students' prior knowledge. In F. Cavas-Martínez et al. (Eds.): INGEGRAF 2019, LNME, p. 10 (2020). https://doi.org/10.1007/978-3-030-41200-5_50

6. Barr R.E.: The current status of graphical communication in engineering education. In: Proceedings of Proceedings - Frontiers in Education Conference, FIE, 2004, vol. 3, pp. S1D-8-S1D. https://doi.org/10.1109/FIE.2004.1408688

7. Barr R.E.: Engineering graphics educational outcomes for the global engineer: an update. Eng. Design Graph. J. 76(3) (2012)

8. Motyl, B., Baronio, G., Uberti, S., Speranza, D., Filippi, S.: How will change the future engineers' skills in the Industry 4.0 framework? A questionnaire survey. Procedia Manuf. 11, 1501-1509 (2017). https://doi.org/10.1016/j.promfg.2017.07.282

9. Ciolacu, M., Tehrani, A.F., Binder, L., Svasta, P.M. Education 4.0 - artificial intelligence assisted higher education: early recognition system with machine learning to support students' success. In: 2018 IEEE 24th International Symposium for Design and Technology in Electronic Packaging, SIITME 2018 - Proceedings, art. no. 8599203, pp. 23-30. https://doi. org/10.1109/SIITME.2018.8599203

10. Metraglia, R., Baronio, G., Villa, V.: Issues in learning engineering graphics fundamentals: shall we blame cad? In: Proceedings of the International Conference on Engineering Design, ICED 2015 (DS 80-10), vol. 10, pp. 31-40 (2015) 
Open Access This chapter is licensed under the terms of the Creative Commons Attribution 4.0 International License (http://creativecommons.org/licenses/by/4.0/), which permits use, sharing, adaptation, distribution and reproduction in any medium or format, as long as you give appropriate credit to the original author(s) and the source, provide a link to the Creative Commons license and indicate if changes were made.

The images or other third party material in this chapter are included in the chapter's Creative Commons license, unless indicated otherwise in a credit line to the material. If material is not included in the chapter's Creative Commons license and your intended use is not permitted by statutory regulation or exceeds the permitted use, you will need to obtain permission directly from the copyright holder. 